\title{
In vitro/in vivo Correlation of Fast Release Mephenamic Acid Microspheres in Humans
}

\author{
Mohamed A. Etman ${ }^{a}$ Ragwa M. Farid ${ }^{b}$ Aly H. Nadac Abdel-Azim R. Ebian ${ }^{a}$

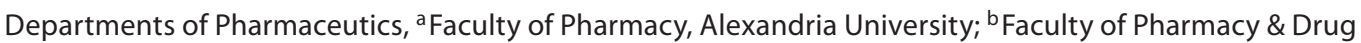

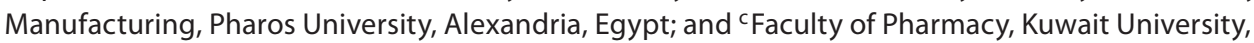 \\ Jabriya, Kuwait
}

\section{Key Words}

Mephenamic acid · Fast release microspheres •

Bioavailability $\cdot$ Healthy volunteers $\cdot$ In vivo/in vitro tests

\begin{abstract}
Objectives: The objectives of this study were to assess the bioavailability of an optimized mephenamic acid (MFA) microspheres (test) against a Ponstan ${ }^{\circledR}$ capsule (reference) in healthy volunteers, and to establish a correlation with in vitro parameters. Subjects and Methods: Four subjects received the test and reference ( $250 \mathrm{mg}$ MFA each) in a randomized crossover design, separated by a 1-week washout period. The drug was analyzed in plasma by a specific highperformance liquid chromatographic method. The relevant pharmacokinetic parameters [maximum plasma concentration $\left(C_{\max }\right)$, time of peak concentration $\left(T_{\max }\right)$, area under plasma concentration-time curves from 0 to $12 \mathrm{~h}\left(\mathrm{AUC}_{0-12}\right)$ and area under plasma concentration-time curves from zero to $\left.\bullet\left(A \cup C_{0-\infty}\right)\right]$ were calculated from the plasma drug concentration-time data. Results: The test product exhibited faster absorption ( $T_{\max }$ of $1.87 \pm 0.482 \mathrm{vs} .2 .14 \pm 0.20 \mathrm{~h} ; C_{\max }$ of $5.91 \pm 0.604 \mathrm{vs} .3 .58 \pm 0.671 \mu \mathrm{g} / \mathrm{ml}$ ) when compared to the reference. The relative bioavailability of the test compared to the reference capsule was $172 \%$. Good correlations were established between the in vitro $90 \%$ dissolution (T90)
\end{abstract}

and each of the $\mathrm{AUC}_{0-12}$ and $\mathrm{T}_{\text {max }}$, as well as between the percentage of drug released and plasma concentrations. Conclusion: The formulation of MFA microsphere with polyethylene glycol improved the dissolution rate and bioavailability of MFA, as evidenced by a higher $C_{\max }, A \cup C_{0-12}$ and $A \cup C_{0-\infty}$, and shorter $T_{\max }$ values. Good correlations between $\mathrm{T} 90$ and both $A \cup \mathrm{C}_{0-12}$ and $\mathrm{T}_{\max }$ as well as between the percentage of drug released and plasma concentrations were achieved.

Copyright $\odot 2011$ S. Karger AG, Basel

\section{Introduction}

Mephenamic acid (MFA), [N-(2,3-xylyl)]anthranilic acid, is a widely used analgesic and anti-inflammatory agent, which is effective in the treatment of rheumatoid arthritis and menstrual disorders $[1,2]$. MFA is characterized by low aqueous solubility $(41 \mu \mathrm{g} / \mathrm{ml})$, therefore the dissolution rate is expected to be limited and the in vivo absorption might be erratic [3]. Many attempts have been made to improve the dissolution rate of poorly water-soluble drugs by dispersion of the drugs in water-soluble carriers [4-6]. Moreover, the bioavailability of MFA has been studied by many investigators [7-9]. Hummel and Buchmann [9] investigated the influence of the par- 
ticle size of MFA on the dissolution and bioavailability of tablets, and found that comminution of MFA resulted in a significant increase in absorption and bioavailability. In a previous work [10], we have reported on the formulation of MFA microspheres by an emulsion congealing method using polyethylene glycol (PEG) 4000 as the coating material and 1\% Span 80 as emulsifying agent. One of the developed formulations (formula $\mathrm{O}$ ) was characterized by a rapid and complete in vitro release of the drug and proved to be physically and chemically stable after storage for 1 year. However, the benefit of the enhanced dissolution of the microsphere formulation needs to be supported with the evidence of enhanced absorption in humans. Therefore, the objectives of this study were to assess the bioavailability of MFA from the selected microsphere formulation (formula $\mathrm{O}$ ) in healthy male volunteers, and establish an in vitro/in vivo correlation. The reference product was a commercial conventional MFA capsule (Ponstan ${ }^{\circledR}$ ) available on the local market.

\section{Materials and Methods}

\section{Materials}

MFA was supplied by Sigma Chemical Co., St. Louis, Mo., USA. Commercial conventional capsules (Ponstan) containing 250 mg MFA were manufactured by El-Nil Co., Cairo, Egypt, under license from Parke Davis, USA. PEG 4000 was procured from Fluka AG, Chemische Fabrik, Buchs, Switzerland, and liquid paraffin from Merkur GmbH \& Co. KG, Hamburg, Germany. Span 80 was obtained from Croda Oleochemicals, UK, and cyclohexane from Adwic-Prolabo Laboratory Chemicals, Cairo, Egypt. Acetonitrile high-performance liquid chromatographic (HPLC) grade was purchased from Romil Chemicals Ltd., Shepshed, UK, and glacial acetic acid from El Nasr Pharmaceutical Chemical Co., Cairo, Egypt.

\section{Preparation of MFA Microspheres}

The effectiveness of MFA in performing the desired therapeutic effects is partly dependent on the formulation in which such a drug is designed. Therefore, on the basis of the previous in vitro data [10], the optimized formulation (formula O) showing the fastest dissolution rate was selected for further bioavailability assessment against Ponstan capsules (250 mg MFA) as a reference product. Formula $\mathrm{O}$ was chosen for the in vivo test based on a high dissolution pattern (more than $90 \%$ of the drug dissolved in $30 \mathrm{~min}$ ) [10]. Moreover, the optimized formulation also exhibited excellent chemical stability after storage for 12 months without a change of the initial dissolution profile. Furthermore, the selected formulation demonstrated a high drug content, encapsulation efficiency and yield: 21, 84.4 and 985, respectively. MFA ammonium salt was first prepared by heating a mixture of MFA and PEG 4000 (1:3 w/w), while ammonia was added dropwise under stirring. The melt which formed was cooled, ground with a pestle and then dried with filter paper and put into a desiccator under vacuum. The microspheres were subsequently prepared us- ing a hot emulsion congealing technique. The aqueous phase (consisting of PEG and the ammonium salt of the drug) and the oil phase (composed of $50 \mathrm{ml}$ liquid paraffin containing $0.5 \% \mathrm{w} / \mathrm{v}$ span 80 as an emulsifier) were heated to $70^{\circ} \mathrm{C}$ prior to emulsification with a mechanical stirrer at 2,000 rpm, to form a W/O emulsion. The drug-PEG hydrophilic phase was used with the oil phase in the ratio of $1: 10 \mathrm{w} / \mathrm{w}$, respectively. Hardening of the aqueous internal phase and the formation of the microspheres were accomplished by pouring equal volumes of ice-cold liquid paraffin $\left(4{ }^{\circ} \mathrm{C}\right)$ into the beakers containing the hot emulsion. The congealed microspheres were separated from the oil phase by filtration with decantation, followed by washing with cyclohexane, drying at room temperature and sieving. The produced microspheres were subsequently sieved and classified into three categories: $400-500,500-630$ and $630-800 \mu \mathrm{m}$.

\section{Bioavailability Study}

Subjects, Products and Design. Four healthy volunteers, age 27-36 years and body weight $60-90 \mathrm{~kg}$, participated in the study after signing consents. The study protocol was approved by the Graduate Studies Committee, Faculty of Pharmacy, Alexandria, Egypt. The health state of each volunteer was ascertained by biochemical blood analysis before the study. The subjects were not administered any other medication for a 1-week period before the initiation of the study and throughout the study period. MFA microspheres (formula $\mathrm{O}$, test) containing the equivalent of $250 \mathrm{mg}$ MFA and filled in hard gelatin capsules (size 0 ) were the test formulation, and Ponstan capsules (250 mg MFA) were the reference. The doses were given to each subject on two separate occasions in a random crossover design, separated by a 1-week washout period. The subjects were given either product along with $250 \mathrm{ml}$ of water following an overnight fasting, which was continued for $4 \mathrm{~h}$ after the dose administration. This was then followed by a standard meal consisting of 4 tablespoonfuls of beans with oil and table salt, 2 boiled eggs, $50 \mathrm{~g}$ of cheese and a loaf of bread. Venous blood samples (5 ml) were collected at 0 (before dose), $0.5,1,1.5,2,3,4$, $6,8,10$ and $12 \mathrm{~h}$ after drug administration. The heparinized blood samples were mixed well, and the plasma fractions were separated by centrifugation and frozen at $-20^{\circ} \mathrm{C}$ pending analysis.

HPLC Analysis of Plasma Samples. After administration of the test (formula $\mathrm{O}$ ) and the reference products to 4 healthy volunteers, blood samples were collected at different time intervals and analyzed for their drug content by HPLC. Plasma concentrations of MFA were quantitated by a rapid and sensitive HPLC method with ultraviolet detection [11]. The HPLC system consisted of a pump (Waters 501, Waters Corp., Milford, Mass., USA), reverse phase column ( $\mu$ Bondapak C18, $10 \mu \mathrm{m}, 3.9 \times 300 \mathrm{~mm}$, Waters Corp.) and a tunable UV absorbance detector (Model 486, Waters Corp.). A sample of $5 \mu \mathrm{l}$ of the internal standard solution (Etodolac $50 \mu \mathrm{g} / \mathrm{ml}$ in the mobile phase) was added to $0.2 \mathrm{ml}$ of plasma in a centrifuge tube. The contents of the tube were mixed by a vortex shaker for $30 \mathrm{~s}$, and precipitation of the plasma proteins was accomplished by the addition of $0.5 \mathrm{ml}$ of acetonitrile. The mixture was then shaken again on a vortex mixer for $1 \mathrm{~min}$ and centrifuged for $10 \mathrm{~min}$ at 2,500 rpm. The clear supernatant solution $(20 \mu \mathrm{l})$ was then injected directly into the HPLC column. Spiked standards were prepared by adding aliquots of MFA standard solutions, 200 and $500 \mu \mathrm{g} / \mathrm{ml}$ in the mobile phase, to $0.2 \mathrm{ml}$ of blank plasma to cover a concentration range from 5 to $25 \mu \mathrm{g} /$ $\mathrm{ml}$. The mobile phase consisted of $\mathrm{CH}_{3} \mathrm{CN}: \mathrm{H}_{2} \mathrm{O}(1: 1 \mathrm{v} / \mathrm{v})$ adjusted 
to $\mathrm{pH} 4.0$ with glacial acetic acid. The flow rate was $1 \mathrm{ml} / \mathrm{min}$, and the eluents were detected at $285 \mathrm{~nm}$. Under such conditions, the retention time for MFA and Etodolac (internal standard) were 10 and 6 min, respectively.

Validation of Assay Methodology. At least 3 standards were injected on each analysis day among the samples analyzed. Peak heights of MFA and Etodolac were measured and the peak height ratios were calculated. The concentration of MFA in each sample was calculated from a peak height ratio using the corresponding linear regression equation relating peak height ratios of standards to their concentrations. The amounts of MFA found were evaluated by refitting the ratios from the calibration standards in the derived regression equation, and their means, standard deviations and coefficients of variation were calculated. Interday precision was assessed by examining the coefficient of variation, calculated for the standards assayed on different days.

Pharmacokinetic Parameters. The mean and individual plasma concentrations were fit to a stripping computer program [12] to calculate the area under the plasma concentration and the other relevant pharmacokinetic parameters. Calculated parameters include peak plasma concentration $\left(\mathrm{C}_{\max }\right)$, time of peak concentration $\left(\mathrm{T}_{\max }\right)$, area under plasma concentration-time curves from 0 to $12 \mathrm{~h}\left(\mathrm{AUC}_{0-12}\right)$, area under plasma concentration-time curves from zero to $\bullet\left(\mathrm{AUC}_{0-\infty}\right)$, the absorption rate constant $\left(\mathrm{K}_{\mathrm{a}}\right)$, the elimination rate constant $\left(\mathrm{K}_{\mathrm{el}}\right)$, the half-life time $\left(\mathrm{t}_{1 / 2}\right)$, the mean residence time (MRT), and the lag time for absorption. These parameters were calculated using the Stripe computer program [12]. A single compartment linear pharmacokinetic model was assumed.

\section{Statistical Analysis}

According to the recommendations of the USP 25 [13], ANOVA tests for crossover design were carried out to assess the effects of sequence, subjects within sequence, periods and treatment on $\mathrm{C}_{\max }, \mathrm{AUC}, \mathrm{T}_{\max }$, and on their log-transformed data (except for $\left.\mathrm{T}_{\max }\right)$. All the effects were tested against the mean square error term. Sequence effects were tested against the mean square term for subjects within the sequence $[13,14]$.

\section{In vitro/in vivo Correlation}

In order to establish a correlation between the in vitro dissolution rate and plasma drug concentration, the percentages of drug released obtained from the in vitro release profiles of the test formulation were plotted along the abscissa, and the plasma concentration $(\mu \mathrm{g} / \mathrm{ml})$ values obtained from the mean plasma concentration-time profile were plotted along the ordinate at the same time intervals.

\section{Results}

\section{In vivo Study}

The mean values of the drug content analyzed by HPLC are shown in figure 1. Validation parameters of the assay were confirmed by the calculation of interday precision data, and small values for SD (0.60-1.29) over a concentration range of $5-25 \mu \mathrm{g} / \mathrm{ml}$ were observed. Linearity was confirmed from the linear regression data, relating

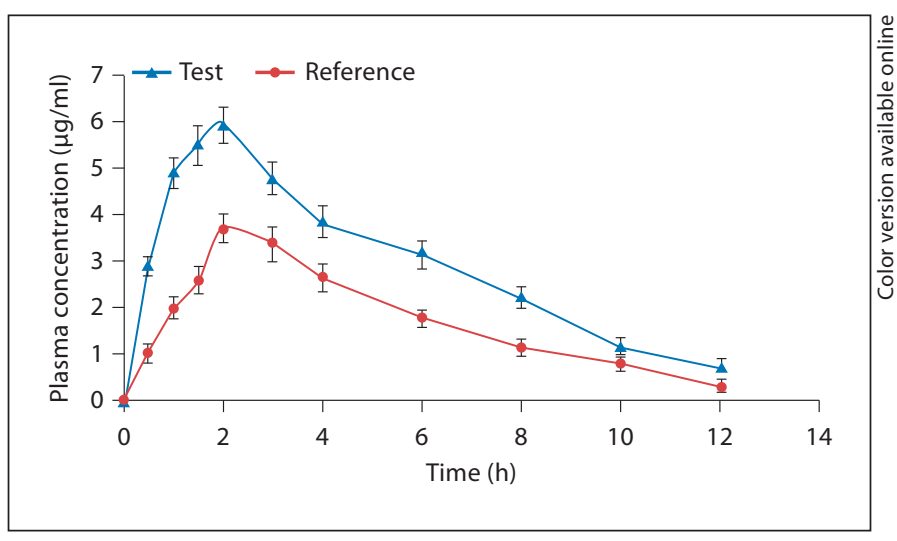

Fig. 1. Mean plasma MFA concentration following the oral administration of fast release microspheres of formula $\mathrm{O}$ (test) and Ponstan capsules (reference), each containing $250 \mathrm{mg}$ MFA.

Table 1. Mean plasma MFA pharmacokinetic parameters following oral administration of formula $\mathrm{O}$ microcapsules (test) or Ponstan capsules (reference), each containing $250 \mathrm{mg}$ MFA, to healthy volunteers

\begin{tabular}{lcc}
\hline Pharmacokinetic parameters & Test $\pm \mathrm{SD}$ & Reference $\pm \mathrm{SD}$ \\
\hline $\mathrm{AUC}_{0-12}, \mu \mathrm{g} \cdot \mathrm{h} / \mathrm{ml}$ & $35.55 \pm 4.38$ & $20.62 \pm 7.412$ \\
$\mathrm{AUC}_{0-\infty}, \mu \mathrm{g} \cdot \mathrm{h} / \mathrm{ml}$ & $38.03 \pm 2.276$ & $22.39 \pm 10.113$ \\
$\mathrm{C}_{\max }, \mu \mathrm{g} / \mathrm{ml}$ & $5.91 \pm 0.604$ & $3.58 \pm 0.671$ \\
$\mathrm{~T}_{\max }, \mathrm{h}$ & $1.87 \pm 0.482$ & $2.14 \pm 0.20$ \\
$\mathrm{~K}_{\mathrm{el}}, \mathrm{h}^{-1}$ & $0.22 \pm 0.056$ & $0.34 \pm 0.127$ \\
Elimination $_{1 / 2}, \mathrm{~h}$ & $3.46 \pm 0.758$ & $2.42 \pm 1.139$ \\
$\mathrm{~K}_{\mathrm{ab}}, \mathrm{h}^{-1}$ & $2.14 \pm 1.852$ & $0.96 \pm 0.208$ \\
Absorption $_{1 / 2}, \mathrm{~h}$ & $0.54 \pm 0.258$ & $0.64 \pm 0.208$ \\
MRT, h $_{\text {Lag time, }} \mathrm{h}$ & $5.72 \pm 0.965$ & $5.06 \pm 1.215$ \\
\hline
\end{tabular}

$\mathrm{K}_{\mathrm{el}}=$ Elimination rate constant; $\mathrm{t}_{\frac{1}{2}}=$ half-life time; $\mathrm{MRT}=$ minimum residence time.

the peak heights and MFA in plasma, with $r$ values very close to unity, 0.987-0.999 (i.e. $\mathrm{y}=0.0041+0.085 \mathrm{x}, \mathrm{r}=$ 0.996).

The mean and individual plasma concentrations of the area under the plasma concentration and other relevant pharmacokinetic parameters are shown in table 1 . The observed mean $\mathrm{C}_{\max }$ after administration of the test product was approximately 1.5 times more than the reference, namely $5.91 \pm 0.60$ and $3.58 \pm 0.67 \mu \mathrm{g} / \mathrm{ml}$, respectively. The fast-release formula $\mathrm{O}$ showed significantly higher mean plasma levels compared with the conven- 


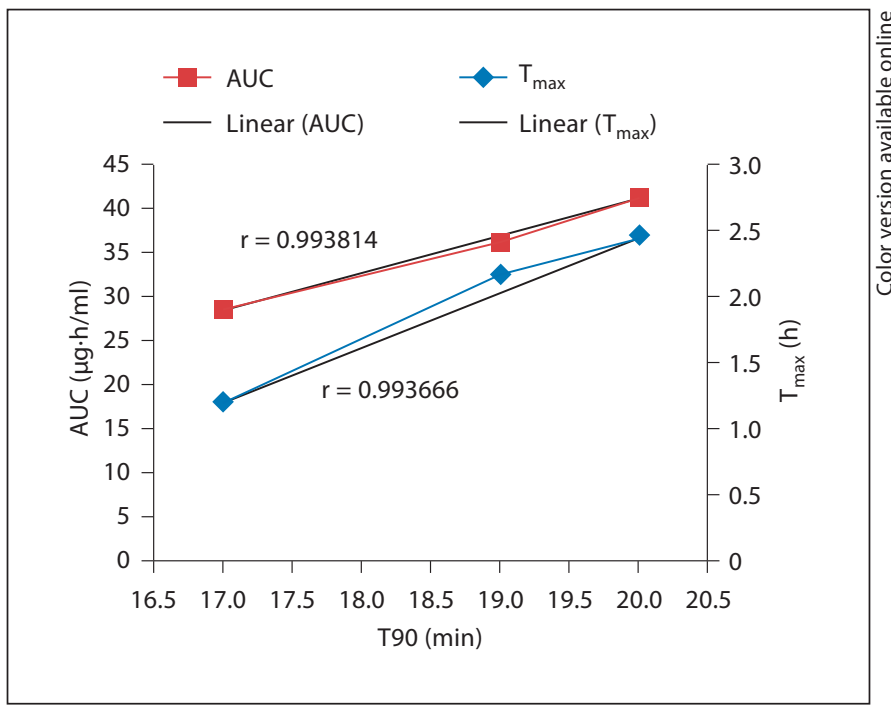

Fig. 2. Correlation of the T90 and the corresponding individual values of each $\mathrm{AUC}_{0-12}$ and $\mathrm{T}_{\max }$ value obtained following the administration of the prepared microspheres containing $250 \mathrm{mg}$ MFA (test) to 3 healthy subjects.

tional reference MFA capsules (fig. 1), as indicated by a shorter mean $\mathrm{T}_{\max }(1.87 \pm 0.48$ vs. $2.14 \pm 0.02 \mathrm{~h}$ ) (table 1). In addition, the test formula $\mathrm{O}$ improved the bioavailability of the drug leading to about a 1.7-fold increase in AUC, 1.6-fold increase in $\mathrm{C}_{\max }$ and a decrease in $\mathrm{T}_{\max }$ $(0.8$-fold) relative to the reference product (table 1$)$.

The calculated pharmacokinetic parameters $\left(\mathrm{C}_{\max }\right.$, $\mathrm{T}_{\max }, \mathrm{AUC}_{0-12}$ and $\left.\mathrm{AUC}_{0-\infty}\right)$ further evaluated statistically by an ANOVA test for crossover design to assess the effects of sequence, subjects within sequence, periods and treatment are shown in table 1 . No statistically significant differences were observed with respect to any of these effects either with plain data or with log-transformed data concerning only the $\mathrm{T}_{\max }$ and $\mathrm{AUC}_{0-\infty}$ values.

\section{In vitro/in vivo Correlation}

A good correlation was obtained between the percentage of drug released and plasma concentration values $(y=0.085 x-4.742, r=0.9664$; data not shown). Furthermore, three individual time to $90 \%$ dissolution (T90; an in vitro parameter indicating the time required to reach $90 \%$ of the drug) values of the same optimized formulation (formula $\mathrm{O}$ ) were plotted against each of the calculated $\mathrm{AUC}_{0-12}$ and $\mathrm{C}_{\max }$ values for 3 volunteers (fig. 2). The data indicated good linear relationships between the T90 and each $\mathrm{AUC}_{0-12}(\mathrm{y}=-39.65+4.03 \mathrm{x}, \mathrm{r}=0.994)$ and $\mathrm{T}_{\max }(\mathrm{y}=-5.79+0.42 \mathrm{x}, \mathrm{r}=0.994)$.

\section{Discussion}

The ratio of $\mathrm{AUC}_{0-12} / \mathrm{AUC}_{0-\infty}$ for all individuals and for the mean in both the test and the reference product was $>0.8$, indicating an adequate sampling time since the extrapolated portion (tail area) of the total AUC (percentage of $\mathrm{AUC}_{12-\ldots} / \mathrm{AUC}_{0-\infty}$ ) was less than $20 \%$.

The mean peak plasma concentrations after administration of the test formula $\mathrm{O}$ to the volunteers were markedly higher than those observed after administration of the reference product (fig. 1), indicating a better absorption from the test formula $\mathrm{O}$. Moreover, the $\mathrm{T}_{\max }$ was shorter for the test, compared to the reference sample (table 1). Although the difference between the $T_{\max }$ values was not statistically significant (table 1), it should be noted that the mean $\mathrm{C}_{\max }(3.58 \pm 0.67 \mu \mathrm{g} / \mathrm{ml})$ attained after $2 \mathrm{~h}$ of the reference administration was the same as the concentration reached after only $0.75 \mathrm{~h}$ following administration of the test product (formula $\mathrm{O}$ ). This further indicates the faster rate of drug absorption from the test formula, which is an advantage for anti-inflammatory and analgesic drugs.

The pharmacokinetics of MFA after oral administration have been investigated previously by some authors $[3,5,15]$. The reported peak plasma level after a 1-gram oral dose was found to be $10 \mu \mathrm{g} / \mathrm{ml}$ [16]. However, after oral administration of $250 \mathrm{mg} 3$ times daily for 4 days to 10 subjects, $C_{\max }$ of $0.3-2.4 \mu \mathrm{g} / \mathrm{ml}$ were attained [17]. The objective of this study was to formulate the drug in such a way to attain peak plasma levels with a smaller dose and fewer side effects. The observed $\mathrm{C}_{\max }$ for the proposed formula $\mathrm{O}$ of this study after a single 250 -mg oral dose was $5.90 \mu \mathrm{g} / \mathrm{ml} \pm 0.60$, which is more than half the value reported in another study after a single 1-gram dose [16]. Therefore, it could be suggested that a 500-mg dose of our proposed formula could probably provide therapeutic plasma levels comparable to those obtained after a 1-gram dose of the untreated drug. The higher $\mathrm{C}_{\max }$ and relatively shorter $\mathrm{T}_{\max }$ values of the test formulation are expected to provide an effective and fast means for the control of pain with comparatively lower doses. It should be pointed out that our product showed consistently remarkable higher plasma concentrations at all time intervals compared with the reference product (fig. 1). These higher plasma concentrations, particularly at early time intervals $(0-2 \mathrm{~h})$, could reflect the fast release nature of formula $\mathrm{O}$ and indicate its superiority over the reference one as well as its promising applicability in treating acute and chronic pains. The higher release rate and faster absorption from the test sample formula $\mathrm{O}$ could also be expect- 
ed to reduce local irritation on gastrointestinal mucosa as a result of a prolonged contact time prior to dissolution and absorption of the drug encountered with other conventional products such as the reference capsule. The reduced local irritation could be due to 2 reasons: firstly, the rapid disappearance of the solid as a result of its fast dissolution and, secondly, the rapid absorption of the dissolved drug. The high relative bioavailability of the test formulation (AUC test/AUC reference $\times$ dose reference/ dose test $=172 \%)$ relative to the reference sample could be of great clinical importance in achieving a better therapeutic plasma concentration, and could be of value in using relatively lower doses of the drug to achieve the desired therapeutic response. This higher bioavailability could be due to the improvement of the dissolution of formula O. Finholt [18] has stated that the rate of the dissolution of drugs from capsules is a complex function of the rates of different processes, such as the solution of the gelatin shell, the penetration of water into the powder mass, the deaggregation of the powder mass and the dissolution of the drug particles. However, despite these complex processes, the drug from a well-formulated product may be released within 5-10 min after oral administration of a capsule [16]. The deaggregation rate and solubility of the drug released into digestive fluids after the disintegration of a capsule have been reported to exert an influence on the absorption of the drug concerned [19, 20].

It is worth mentioning that the existence of a marked significant statistical difference related to treatment on both plain data and log-transformed data regarding $\mathrm{C}_{\max }$ and plain data of $\mathrm{AUC}_{0-12}$ suggests that these products are not interchangeable. This was clearly obvious due to the great difference in percent bioavailability of the test product relative to the reference one (172\%).

\section{Conclusion}

The data showed that formula $\mathrm{O}$ had an increased dissolution rate and resulted in a marked improvement in the bioavailability of the drug as evidenced by a higher $\mathrm{C}_{\text {max }}$, extent of absorption, $\mathrm{AUC}_{0-12}$ and $\mathrm{AUC}_{0-\infty}$. Good correlations between $\mathrm{T} 90$ and each $\mathrm{AUC}$ and $\mathrm{T}_{\max }$, as well as between the percentage of drug released and plasma concentration were achieved. Hence, formula $\mathrm{O}$ could also be useful as a fast-release preparation for the treatment of acute pain and inflammation. Although the results obtained in this investigation are promising, further studies may be required in order to investigate the behavior of the drug from the proposed formulation after repeated dose administration.

\section{References}

1 Parfitt K (ed): Martindale: The Complete Drug Reference, ed 32. London, Pharmaceutical Press, 1999, pp 51-52.

2 Gray M, Nouehed LA: PDR Generics: The Information Medical Standard For Prescription Drugs, ed 3. Montvale, Medical Economics, 1997, p 2022.

3 Rawashdeh NM, Najib NM, Jalal IM: Pharmacokinetic behaviour of two tablet formulations of mefenamic acid in healthy volunteers. Saudi Pharm J 1997;5:56-61.

4 Chiou WL, Reegelman S: Pharmaceutical applications of solid dispersion systems. J Pharm Sci 1971;60:1281-1302.

5 Westerberg M, Jonsson B, Nystrom C: Physicochemical aspects of drug release IV. The effect of carrier particle properties on the dissolution rate from ordered mixtures. Int J Pharm 1986;28:23-31.

-6 Ramadan EM, Abd-el Gawad AH, Nouh AT: Bioavailability and erosive activity of solid dispersions of some non-steroidal anti-inflammatory drugs. Pharm Ind 1987;49:508513.

-7 Hamaguchi T, Shinkuma D, Yamanaka Y, Mizuno N: Bioavailability of mefenamic acid: influence of food and water intake. J Pharm Sci 1986;75:891-893.

In vitro/in vivo Correlation of Fast

Release Mephenamic Acid Microspheres
8 Imai T, Nohdomi K, Acarturk F, Otagiri M: Enhancement of dissolution and absorption of mefenamic acid by egg albumin. J Pharm Sci 1991;80:484-487.

$\checkmark 9$ Hummel D, Buchmann S: Influence of mefenamic acid particle size on the dissolution and bioavailability of tablets. Pharm Ind 2000;62:452-456.

10 Etman M, Farid R, Nada A, Ebian A: Preparation and evaluation of fast release mephenamic acid microspheres. J Microencapsul 2010;27:640-656.

11 Etman MA, Abdel-Hamid MH: A new HPLC method for the determination of ketoprofen in plasma and its application in bioavailability and pharmacokinetic studies. Alex J Pharm Sci 1990;4:32-36.

12 Johnston A, Woollard RC: STRIPE: an interactive computer program for the analysis of drug pharmacokinetics. J Pharmacol Methods 1983;9:193-200.

13 USP 25, NF 20: United State Pharmacopeial Convention, Rochville, MD, USA, 2002, p 2165.

14 Bolton S: Drugs and the Pharmaceutical Sciences, Pharmaceutical Statistics, Practical and Clinical Applications, ed 3. New York, Dekker, 1997, vol 80, pp 384-442.
15 Moffat AC, Jackson IV, Moss MS, Widdop B: Clarke's Isolation and Identification of Drugs in Pharmaceuticals, Body Fluids and Post-Mortem Material, ed 2. London, Pharmaceutical Press, 1986, p 727.

16 Shinkuma D, Hamaguchi T, Yamanaka Y, Mizuno N: Correlation between dissolution rate and bioavailability of different commercial mefenamic acid capsules. Int J Pharm 1984;21:187-200.

17 Dollery SC: Therapeutic Drugs, ed 2. Edinburgh, Churchill Livingstone, 1991, vol 2, pp M31-M34.

18 Finholt P: Influence of formulation on dissolution rate; in Leeson LT, Cartensen JT (eds): Dissolution Technology. Washington, Industrial Pharmaceutical Technology Section of the Academy of Pharmaceutical Science, 1974, pp 106-146.

19 Aguiar AJ, Wheeler LM, Fusari S, Zelmer JE: Evaluation of physical and pharmaceutical factors involved in drug release and availability from chloramphenicol capsules. J Pharm Sci 1968;57:1844-1850.

20 Samyn JC, Jung WY: In vitro dissolution from several experimental capsule formulations. J Pharm Sci 1970;59:169-175. 